\title{
Os sentidos da infância: um estudo sobre processos subjetivos na instituição escolar
}

\author{
Miriam Aparecida Graciano de Souza Pan \\ Carlos Alberto Faraco \\ Universidade Federal do Paraná, Curitiba
}

\begin{abstract}
RESUMO
Este estudo teórico investiga os sentidos atribuídos ao desenvolvimento da criança ao longo do processo de escolarização na modernidade, relacionando-os às formas de inclusão/exclusão geradas ao longo do letramento. Analisa, por meio da teoria crítica da cultura e da análise do discurso, os fundamentos do processo de teorização da infância em sua relação com o iluminismo, e seus efeitos de sentido sobre a trajetória escolar da criança. Relaciona estes sentidos à prática institucional homogeneizadora, acenando a possibilidade de pensarmos que a teorização da infância em seus modelos mais avançados constitui dispositivos de normalização que fortalecem a barra entre o normal e o patológico na escola. Identifica nas práticas discursivas pedagógicas as formas possíveis de melhor preparar a criança para o amanhã, representando um verdadeiro mito da evolução, no qual consolidase uma forte crença em uma subjetividade nuclear, centrada e presente a si mesma, que se desenvolve independente das práticas pedagógicas. Conclui afirmando que os efeitos dos discursos pedagógicos são constitutivos dos modos de subjetivação infantil, considerando outra possibilidade de pensar a criança e a educação a partir da ressignificação dos sentidos da experiência escolar.
\end{abstract}

Palavras-chave: infância; processos subjetivos; inclusão/exclusão.

\begin{abstract}
The childhood meanings: a study on the subjective processes at school

The present theoretical study investigates the interrelation between child development meanings and forms of inclusion/exclusion in the modern school education process. It analyses the childhood theorization process interrelation with Iluminism and the effects of such meanings on the child school history through the theory of cultural criticism and discourse analysis. The study establishes a relation between those meanings and the homogenizing institutional practice and suggests the possibility that the most advanced childhood theorization models constitute the normalization tools that strengthen the limit between normal and pathologic at school. It also identifies the best possible ways to prepare children for the future within the pedagogic discourse practices, thus being a true evolution myth which consolidates a strong belief in a nuclear subjectivity that is self-centered, presented and developed independently from the pedagogic practices. Finally, it states that the pedagogic discourse effects compose the child subjectivity forms . The study also suggests that another way to understand children and education is to give a new meaning to school experiences.
\end{abstract}

Keywords: childhood; subjective processes; school inclusion/exclusion.

\section{INTRODUÇÃO}

Este estudo discute alguns caminhos teóricometodológicos que direcionam a análise da relação infância-escola. Mais precisamente, situa-se a questão: qual o lugar que a criança vem ocupando nos discursos que a enredam nesta relação? Tal indagação conduz nossa pesquisa à análise dos sentidos atribuídos ao desenvolvimento da criança no processo de escolarização na modernidade, relacionando-os às formas de inclusão/exclusão geradas ao longo do letramento.

Partimos da seguinte hipótese: as teorias da infância que fundamentam os discursos pedagógicos contemporâneos, em seus modelos mais avançados, orientam-se por pressupostos cognitivos, gerando uma ilusão de autonomia da criança, compreendida como um ser raciocinante normal. Esta forma de compreen- 
dê-la oculta a ordem discursiva que a produz, bem como as estratégias produzidas pos seus efeitos de classificação dos desvios e das patologias que a tornam inapta à carreira escolar. Assim, as diferentes formas de pensar, sentir, agir e se expressar da criança passam por uma prática institucional homogeneizadora, ou seja, são atravessadas por um crivo normalizador e, conseqüentemente, são capturadas por uma rede de sentidos que lhes atribui existência enquanto déficit ou deficiência.

Considerando o exposto, esta pesquisa investiga a relação entre conhecimento e infância na instituição escolar, partido da perspectiva bakhtiniana da análise dos discursos escolares e da teoria críca da cultura. Para tanto, realizou-se um estudo sobre o processo histórico da modernidade e a noção de infância dele decorrente, seu surgimento e sua inserção nas práticas discursivas contemporâneas, sua relação com o modo dominante de conhecimento e o processo de desenvolvimento da razão iluminista. Em seguida, passa-se a relacionar os sentidos atribuídos à infância ao processo de normalização escolar enquanto estratégia de produção subjetiva atrelada a uma ordem discursiva que efetua processos de inclusão e exclusão.

\section{Infância e Conhecimento na Modernidade}

O conhecimento da infância, da saúde, do desenvolvimento e educação da criança esteve, no último século, nas mãos de especialistas, que cuidaram de sua sobrevivência e de sua educação, de modo a lhe garantir a passagem, em outros tempos tão difícil, para a vida adulta. A criança, tal qual o ser humano de modo geral, torna-se, como resultado do projeto iluminista, passível de investigação científica, ajustando-se ao modelo axiomático das ciências naturais. Tal afirmação remete-nos à questão: Qual a relação entre os fundamentos deste projeto e o conhecimento que circula na escola sobre a criança?

O iluminismo, segundo Horkheimer e Adorno (1985), pode ser compreendido como uma tradição cultural que se define pela postura crítica e pelo combate a todas as tradições. Tem por objetivo libertar o ser humano para o desempenho, e, com seu poder técnico e manipulatório sobre a natureza, domá-la e submetê-la às suas próprias finalidades. Os temores das forças obscuras que dominavam até então devem ceder ante a crítica livre e racional, da qual se espera a quebra de todos os bloqueios que limitem o progresso de seu domínio técnico e prático.

Essa tradição cultural teve como prática a incessante separação entre sujeito e objeto, ambos purificados e abstraídos de suas determinações no fundo comum, na experiência, para se defrontarem com entidades auto-subsistentes e antagônicas no contexto das práticas produtivas e dos procedimentos científicos.

Tem seu ponto culminante na Idade Moderna, trazendo a exaltação do sujeito como senhor do universo, e também como precondição para o exercício do poder - a exaltação do objeto. Conhecer representou, para esse projeto, dominar a realidade, suplantar a tensão entre arcaico/moderno, mito/razão, no sentido de ir da submissão ao senhorio, sendo o saber o principal instrumento de exploração da realidade.

A partir desse projeto a criança passa a ser reconhecida como objeto de estudo da ciência (sujeito que conhece), e o conhecimento acerca da infância, acompanhando a evolução do pensamento ocidental, deixa de ser do domínio mítico e desconhecido para tornarse objeto da razão instrumental.

Contudo, a hegemonia da razão - única forma de conhecer e dominar as forças da natureza - impõe conseqüências necessárias, como a unidade do método e do objeto. Assim, o conceito moderno de ciência assume a verdade como certeza, em sua tarefa de organizar, catalogar o real, transformando a relação do ser humano e seus modos de produção.

A modernidade, desse modo, coloca o problema do conhecimento da criança como tarefa da ciência e se depara com a seguinte contradição: para conhecê-la deve tomá-la como outro objeto qualquer, abstraindoa de sua realidade, universalizando-a, unificando-a em modelos que acabam por traçar uma certa trajetória comum. Se conhecer é dominar a natureza e seus objetos, conhecer é também controlar. Assim, essa ciência que conhece acaba por controlar e prescrever o desenvolvimento infantil.

Ademais, esse modelo de ciência, ao estudar o ser humano, adere ao estilo de pensamento das ciências naturais e propicia uma série de reificações que acabam por desumanizar o indivíduo da mesma forma que os sistemas políticos e ideológicos o fazem. Adere a um universo de pensamento formal, aproximando as pessoas das coisas e apagando suas diferenças. Os fenômenos humanos são muitas vezes naturalizados para melhor enquadramento nos moldes de pesquisa dominante. Como conseqüência, perde-se de vista o laço entre o ser humano e a sua experiência cotidiana. Tal ciência, nesse caso, trata do seu objeto - a criança como outro objeto qualquer; para isso, emudece-o.

Acrescenta-se que, ao incorporar a natureza humana em uma análise científica, isto é feito a partir da biologia, que com ela carrega todo o reducionismo e o determinismo biológico - "a natureza humana é definida pelos nossos genes". Na biologia a herança ge- 
nética é invocada como expressão de inevitabilidade. Entre as conseqüências disso pode-se ressaltar a redução da análise dos fenômenos sociais a uma somatória de comportamentos individuais, estes tratados como coisas e reificados como propriedades localizadas no cérebro de indivíduos particulares, passíveis de mensuração por meio de uma escala qualquer. Estabelecem-se, assim, normas gerais para as propriedades, sendo qualquer desvio à norma, num indivíduo, interpretado como anomalia, que pode refletir problemas médicos dos quais o indivíduo deve ser tratado. Tais características reificadas e identificadas em termos médicos são causadas por acontecimentos no cérebro dos indivíduos. Assim, as características do comportamento humano são definidas como naturais, são entendidas como biologicamente determinadas, portanto, inevitáveis e imutáveis, imputando-se os problemas sociais à natureza (Lewontin, Rose \& Kamin, 1984, p.25-27).

Os conflitos geradores de desigualdades humanas são ocultados, naturalizados e dissociados dos processos subjetivos. A subjetividade é tratada como algo que se situa fora das relações, particularmente dos sentidos produzidos pelos efeitos de poder dos discursaos instituidos, sob os quais a criança vive seu cotidiano.

Os estudos sobre a criança, inicialmente em suas características descritivas e empíricas, passando pelos modelos universalizantes, até as mais sofisticadas arquitetônicas cerebrais que aproximam o ser humano da máquina - a metáfora do computador -, embora simuladamente sociais, não deixaram, nem de longe, suas bases estruturadas no naturalismo e no determinismo biológico.

Mesmo a última geração de modelos teóricos com ênfase na construção dos processos subjetivos, como os interacionismos e construtivismos, não parece desestabilizar a forte crença em uma subjetividade nuclear, centrada e presente a si mesma, que se desenvolve independente das práticas pedagógicas. Pois basta que se apresente à escola uma criança com algum tipo de doença ou deficiência para que os tratados sociais de tais teorias comecem a ruir. Tão logo se iniciam as dificuldades (da própria escola, geralmente oculta, ou do aluno, explicitada), volta-se para o tipo de síndrome da criança, suas relações comportamentais e as pressuposições decorrentes acerca do futuro desempenho de seu portador. Ou seja, a análise cotidiana do fracasso escolar parece condenada ao signo da patologia individual. E este procedimento ocorre de forma tão natural quanto a chuva ou o vento. Embora o ser humano seja de um domínio imprevisível, as teorias parecem dominá-lo, controlá-lo e determiná-lo.
Tal suspeita leva-nos a afirmar que corremos o risco de nos deixar falar pelos grandes sistemas teóricos, que em última instância não apenas falam por nós, mas por aqueles que consideramos sem voz, nossos enfants (sem fala), que tão logo começam a falar devem afinar-se ao coro univocal do discurso pedagógico; ou por aqueles que, impedidos de falar "naturalmente", são mais facilmente colocados à margem de um movimento natural e espontâneo de desenvolvimento da sociedade, em que devem triunfar os mais capazes, em função de suas potencialidades.

Se no século XVIII triunfou o movimento intelectual e cultural em sua pretensão de dominar a problemática do homem pela razão, com a biologia do século XIX esse projeto se concretizou. A crise social desencadeada pela revolução industrial na virada do século XVIII para o XIX, o sistema econômico e político que passa a triunfar, aliados à consolidação do método científico como meio de interpretação da realidade, definem novas formas de organização social. É também nesse bojo que a liberdade, fundamentada juridicamente, ganha sentido com base na igualdade, assegurando a proteção de determinados interesses em nome dos interesses de todos os indivíduos. Nasce uma outra ordem para explicar as desigualdades, a qual, inscrita em um ideal de ordem e progresso, acaba por definir um novo modo de conhecer o ser humano, que o prescreve, que o idealiza, e que quanto mais o investiga mais se distancia de sua experiência cotidiana.

A sociedade regulada e planificada acaba por submeter o ser humano ao mais estrito controle, trazendo para as ciências humanas uma definição de homem que peca por omiti-lo, ou uma ciência que o define pela sua ausência.

Testemunham-se, assim, inúmeras análises que insistem em buscar a criança onde ela se iguala - nas fases, etapas e médias padronizadas, nas notas, nos quadros patológicos, nas síndromes -, isto é, justamente onde ela se esconde. Análises que descartam a criança, seu dizer, seu saber, em favor de um saber que a delimita, que a prescreve para a vida e que a emudece.

Concluída a tarefa inicial de anunciar a forma de conhecimento dominante sobre a criança, relacionando-a ao desenvolvimento da razão iluminista, pretende-se delinear o caminho a seguir: encontrar elementos históricos e filosóficos de análise que permitam captar as origens dos discursos sobre a criança na escola. 


\section{A Análise da Produção dos Sentidos sobre a Infância: um Diálogo entre História, Filosofia e Psicologia}

Inúmeras são as definições teórico-científicas que embasam as pedagogias da criança, as quais se diferenciam por suas práticas metodológicas, muito embora se igualem em seus projetos, destinados a transformar nossos enfants em seres dotados de razão. É preciso evidenciar, no entanto, que a noção de infância, aparentemente natural e a-temporal, é relativamente nova, como nos mostra o historiador francês Philippe Ariès, e consequiente ao triunfo do individualismo burguês do Ocidente e seus ideais de felicidade e emancipação. Sua emergência está localizada no século XVIII. Trata-se, segundo o estudo iconográfico do autor, de uma noção profundamente histórica.

Ariès (1981) mostra que a consciência da particularidade infantil que distingue a criança do adulto não existia até a idade medieval. Um novo sentimento em relação à criança, contraditório em sua natureza, começa a surgir a partir do século XVI, a paparicação, justamente atribuído às mães e amas, vindo com ele também o sentimento de exasperação que revela uma sensibilidade à presença da criança, o que a torna indesejável junto aos adultos. O sentimento de paparicação para com as crianças causa repugnância em educadores e moralistas do século XVII e vai inspirar toda a educação até o século XX. O apego à infância, sua particularidade, não se exprimia mais através da distração e da brincadeira, mas do interesse psicológico e da preocupação moral. A infância passa a representar um tempo de insipidez que repugna à razão. A preocupação passa a ser no sentido de tornar as crianças honradas e probas; homens racionais.

Os dois sentimentos da infância que surgem nos séculos XVI e XVII, embora de origens contraditórias, somam-se a uma preocupação com a higiene e saúde física, tornando a criança um assunto sério e digno de atenção.

Até então, a criança, apesar de se relacionar com os adultos, não tinha especificidade que a representasse em suas particularidades. Era uma redução do adulto - não possuía um lugar na representação cultural, apesar de imersa em sua cultura, nas épocas passadas. Essa representação começa a surgir com sentimentos diferenciados a partir do século XVI, e toma seu lugar central nas preocupações das famílias no século XVIII: sobrevivência, educação e saúde.

A nova configuração da infância irá requisitar novos conhecimentos acerca das necessidades da criança, de seu desenvolvimento físico e mental, de sua educação. Funda-se, assim, uma nova relação entre a criança e o conhecimento, e abre-se espaço para o desenvolvimento de vários campos de saber, como é o caso da psicologia e da pedagogia. Antes, contudo, de abordar os novos sentidos e práticas desenvolvidas a partir desses campos do saber, abrimos espaço para uma reflexão filosófica contemporânea em busca de pistas para pensar esta relação.

O marco da concepção moderna da infância, segundo Gagnebin (1997, p. 170), é o livro de JeanJacques Rousseau, que transforma a prática pedagógica de boa parte da elite esclarecida. A autora aponta as relações que considera estreitas e antigas entre o pensamento filosófico e a noção de infância, traçando o percurso esclarecedor que extrapola os limiares da idade moderna, passa pela idade medieval e chega até Platão, diferenciando duas grandes linhas de pensamento. A primeira nasce com Platão, atravessa a pedagogia cristã com Santo Agostinho e chega até nós através do racionalismo cartesiano. Essa corrente nos diz que a infância é um mal necessário, aproximandoa a um estado primitivo, quase animalesco; a criança deve ser corrigida em suas tendências selvagens e egoístas, que ameaçam a construção consensual da cidade humana graças à edificação racional, o que requer sacrifício das paixões imediatas e destrutivas.

A segunda tem sua origem também em Platão, atravessa o renascimento com Montaigne e chega às nossas escolas alternativas por meio do romantismo de Rousseau, para quem a verdadeira educação se dá por meio do preparo adequado das almas, por impulso próprio e natural, dentro do interesse particular de cada criança, fazendo crescer e desenvolver-se a inteligência de cada um.

Em princípio contraditórias, ambas originam-se do mesmo discurso, na medida em que o pensamento ardiloso da criança e ao mesmo tempo cheio de potencialidades não possui orientação reta, precisa de alguém que o vigie e controle, requer domesticação e adestramento pelas forças da razão, do bem tanto ético quanto político. Por outro lado, enfatiza a capacidade humana de aprender como uma faculdade inata, universal e natural.

O germe das duas correntes presentes em Platão traça, por um lado, o caminho que reivindica o direito à independência da razão, criando condições propícias ao crescimento da luz natural da alma, a razão cartesiana, sem medo da independência e autonomia. Motivos estes caros ao iluminismo, conforme afirma Gagnebin (1997), ao identificar na mediação conceitual entre pensamento filosófico e infância a presença de uma certa concepção de natureza e uma certa concepção 
de razão. Permeada pela desconfiança na natureza da infância (marcada pelo pecado ou erro) e pela confiança na pureza e no poder da razão (rastro da inteligência divina em nossa alma), a infância representa o outro ameaçador da razão, mas é ao mesmo tempo o terreno exclusivo de sua eclosão. Por outro lado, há uma inversão na representação da infância, pois se desconfia da razão para se confiar na natureza.

Da clareza da razão passamos à sinceridade do sentimento. Da infância como território do pecado, a uma "infância como paraíso, perdido, mas próximo" (Gagnebin, 1997, p. 180).

A autora abre pistas para uma reflexão filosófica contemporânea a partir desse campo de ressonância entre infância e pensamento. A primeira delas vem com o conceito de experiência. A infância guarda a experiência preciosa e essencial ao homem em relação a seu desajustamento diante do mundo, de sua não soberania.

A infância é assim o signo que revela a humanidade do homem em sua força e poder, e também, de maneira secreta, suas faltas e fraquezas. A segunda pista talvez possa nos indicar o que há de mais verdadeiro no pensamento humano: sua incompletude, o que é também a invenção do possível.

Tal reflexão impõe-nos o desafio de rever nossa posição frente à experiência da infância, como tão bem o fizeram Jobim e Souza (1994; 1996; 2000), Castro e Jobim e Souza (1994), Pereira e Jobim e Souza (1998), procurando acompanhar os desvios da criança e neles buscar novas maneiras de refletir questões da infância e do conhecimento na contemporaneidade.

Reconhecendo o projeto iluminista como o marco de conhecimento sistematizado sobre a infância, as autoras apontam que é também nele que surge a negação à sua suposta condição de incompletude, uma vez que o que interessa é que ali está um pequeno adulto, "o homem de amanhã". Assim, investe-se em modos apressados de tornar essa fase passageira e efêmera, um amadurecimento que precisa ser aligeirado, pois a vida moderna, caracterizada por contradição e pressa, desde a revolução industrial passou a se seduzir pela idéia de utilidade, produtividade e lucro, associando tempo e dinheiro. "A idéia de ordem e progresso, trazida à tona pela revolução industrial e pelo conceito darwinista de evolução, consolida-se por meio do capitalismo monopolista e faz das teorias positivistas seu ponto alto de sustentação." (Pereira \& Jobim e Souza, 1998, p. 28-30).

Nesse contexto, uma certa noção de história põe em encadeamento dimensões bem definidas de passa- do, presente e futuro, cristalizadas por leis de causalidade e desdobradas em conceitos de causa e conseqüência. Diante de um método universalizador e unitário, esta ciência diretiva conduz à previsibilidade do tempo, da história e da vida.

O tempo previsível é o futuro, no qual o sujeito, a criança neste caso, se tornaria "sujeito da razão". Sua história, portanto, toma a forma de um fluxo contínuo, linear, voltado para o futuro. O que se visa é ao aperfeiçoamento do ser humano ao longo do seu desenvolvimento, para que chegue o mais consciente possível à idade da razão.

Esse questionamento é lançado para o projeto da psicologia do desenvolvimento, o qual cumpre a tarefa de desenvolver a noção de infância no projeto iluminista.

As pesquisas psicológicas percorreram, durante muitos anos, explicações para as mudanças na infância baseadas em modelos empiristas ou em conceitos universalizantes e abordagens teleológicas, demarcando, por meio de fases ou estágios de desenvolvimento, ou mesmo por meio de idade cronológica, o lugar social dos sujeitos. A criança é normalmente tomada como um organismo em formação, fragmentada em áreas de comportamento cuja articulação teórica posterior tenta resgatá-la em sua totalidade enquanto ser ideal, sem resgatá-la no tempo e em sua história concreta de vida. É vista como um organismo em processo de socialização, cuja constituição não se vincula à história e à sociedade.

O processo de socialização da infância, que se dá, via de regra, mediado pela instituição escolar, acaba por se tornar o meio de capacitação dos sujeitos à vida social produtiva, como forma de cadastramento à vida adulta. Com esta ênfase, a escola surge como a principal implicada nas definições dos padrões de normalidade e deficiência, reiteradas por diversos modelos da psicologia do desenvolvimento, que são valorizados nas formas clássicas de diagnóstico. A principal crítica que se pode fazer a essas concepções de infância, como argumenta Jobim e Souza (1996, p. 46), é que:

...as teorias do desenvolvimento humano têm fornecido os elementos necessários para a legitimação científica de um crescente processo de racionalização e institucionalização da infância e da adolescência (...) A psicologia do desenvolvimento é modeladora das formas específicas de subjetividade, cuja matriz é a situação histórica e social do homem moderno, submerso nas exigências de um ideal de sujeito produtivo e consumidor. 
A autora explicita o caráter modelador deste campo de conhecimento, que se coloca, em seu progressivo processo de desenvolvimento, independente de motivos políticos e ideológicos, reduzindo a explicação do desenvolvimento humano a fatos naturais. $\mathrm{Na}$ tentativa de garantir uma neutralidade político-ideológica, acaba produzindo um discurso desenvolvimentista, que acomoda tanto uma certa concepção de natureza, quanto de razão, estipulando formas e possibilidades para o curso da vida humana.

Assim, a criança é vista como objeto, tomado pelos paradigmas hegemônicos presentes nas ciências humanas do século passado, que transformaram o ser humano em matéria inerte, fragmentando-o, homogeneizando o real e impondo-lhe a frieza dos sistemas formais.

Esse modo de tratar as realidades humanas impõe uma forma de compreensão da infância nas sociedades complexas definidora dos padrões de normalidade para o curso da vida e impede a possibilidade de compreender a criança como ser transformador e criador de significações. Os sentidos da infância, assim constituídos, condenam a criança ao signo da estabilização e homogeneização, que refrata em seu reverso a anormalidade. Consolida-se um verdadeiro mito da razão e da evolução. A criança representa o projeto da normalidade pensante do ser humano, tornando-se refém dos processos seletivos e classificatórios presentes nas práticas escolares.

Esse modelo, por sua vez, é difundido pela Psicologia do Desenvolvimento, que estabelece o sentido para o curso da vida humana. Isto significa afirmar que a psicologia, na tentativa de iluminar o desconhecido trajeto da vida humana, termina por estruturar a experiência da criança. Significa também reconhecer que a psicologia cumpre seu papel enquanto operação constitutiva sobre os sujeitos em formação, pois suas interpretações permitem a produção e o consumo de conceitos pelo conjunto da sociedade.

Dessa forma, a infância, tempo e lugar de passagem, de imaturidade, é marcada pela linearidade. Esses modos de experimentar a temporalidade denunciam as atitudes culturais que revelam práticas de controle do tempo futuro, colocando-o na mais absoluta previsibilidade. A criança é submetida a várias atividades para que seja preparada da melhor forma possível para o amanhã. Ganha seus selos de qualidade - verdadeiras senhas identitárias de passagem para a vida adulta. As crianças, sob o efeito dessas práticas, compreendem a escola como o local em que lhes será dado o direito de ser alguém na vida. São levadas a acreditar que sua felicidade, sua liberdade, só podem ser alcançadas pela sujeição a elas.
O desencantamento da criança pelo conhecimento positivo foi uma tarefa que lhe garantiu a sobrevivência. Entretanto, também gerou sentidos definidores das práticas pedagógicas contemporâneas, que visam a aligeirar seu crescimento, sem levar em conta sua peculiaridade, pois deixou de se nutrir da experiência infantil como fonte de indagação da realidade, para se abastecer nas fontes da soberania da razão, comprometendo-se com a produção de modos subjetivos homogeneizadores e massificados.

Essa afirmação nos conduz à seguinte indagação: Como a escola, com seus ideais de igualdade e liberdade, com sua promessa de felicidade, consegue elidir seu papel na produção de modos de subjetivação que implicam submissão, exclusão? A pergunta nos leva a aprofundar nossa pesquisa, colocando em evidência a relação entre as instituições da Modernidade e a experiência humana.

\section{O Mito da Evolução e o Processo de Normalização}

Enguita (1989) aponta o papel socializador da escola, indicando, entre suas principais funções, sua conexão com o mundo do trabalho. Desde o funcionalismo, até os estudos de vários historiadores e sociólogos da educação, já se aponta esta função da escola em legitimar a ordem social existente, reconciliando as pessoas com seu destino social. Contudo, é flagrante o fato de se fazer da experiência escolar uma forma de inserção não conflitiva no mundo do trabalho, "como a panacéia da natureza e da racionalidade e não como algo socialmente determinado, histórico e contingente" (Enguita, 1989, p. 159).

Desse modo, somos incitados a assumir um distanciamento para repensar a modernidade, a fim de analisar o invisível existente no discurso da educação, ou a outra face dos supostos valores liberais e igualitários da escola. Para isso, faz-se necessária a análise de uma série de mudanças que têm origem no renascimento, inter-relacionadas no que se refere ao campo dos saberes, às relações entre poderes e saberes específicos, bem como entre eles e os modos de subjetivação ou os diferentes tipos de identidades sociais que se instituíram.

Com a nova concepção de infância e a separação cada vez mais marcada entre o mundo do adulto e o mundo da criança, surge a necessidade de pôr em ação formas específicas de educação, dando origem a novas instituições educacionais. Surge a necessidade de controlar os saberes a serem transmitidos, organizando-os de forma a adequá-los às capacidades infantis, pondo em prática alguns procedimentos que gradualmente são aperfeiçoados no sentido de conferir aos 
colegiais e aos saberes uma natureza moralizada e moralizante.

Segundo Varela (1994), esses procedimentos tornam-se instrumentos privilegiados da extração de saberes dos próprios escolares, bem como fonte de exercício de poderes que possibilitam o surgimento da ciência pedagógica; do saber pedagógico. Surgem e se aperfeiçoam nos colégios jesuítas e, através de transformações e re-interpretações, estendem-se a outras instituições educacionais de sua época e de épocas posteriores. Seus efeitos são conhecidos como a pedagogização dos conhecimentos.

Sob um novo tipo de análise, Foucault (1987) retrata o múltiplo e imenso combate que se trava no campo do saber em relação com a formação e o exercício de determinados poderes, denominado por ele disciplinarização interna dos saberes.

$\mathrm{O}$ autor nos mostra como a disciplinarização dos saberes esteve ligada, a partir do século XVIII, a modos de subjetivação específicos, colocando em ação tecnologias disciplinares destinadas a conformar sujeitos dóceis e úteis ao mesmo tempo. Trata-se de "métodos que permitem o controle minucioso das operações do corpo, que realizam a sujeição constante de suas forças e lhes impõem uma relação de docilidade-utilidade" (Foucault, 1987, p. 118). São as chamadas disciplinas. Elas tornam-se formas de dominação diferentes da escravidão e da domesticidade. É o momento em que nasce uma nova arte do corpo humano, que visa mais que ao aumento de suas habilidades, mais que à sujeição; visa a uma nova forma de relação, que, pelo mesmo mecanismo, torna-o tanto mais obediente quanto mais útil. Aumenta as forças do corpo, em termos de aptidão, capacidade - em termos econômicos e sua utilidade -, ao mesmo tempo em que diminui essas mesmas forças, fazendo delas uma relação de sujeição estrita - em termos políticos de obediência -, dissociando, assim, o poder do corpo. As relações de poder e os conflitos de classes são eliminados, levando-nos a pôr em funcionamento o contrato social, tornando os Estados a expressão da vontade geral.

A disciplinarização foi decisiva para colocar em ação os sistemas de democracia funcional existentes desde então nos países do Ocidente, tanto do ponto de vista econômico como político e social, pois permitiu tornar aceitável a rentável ficção de que a sociedade é formada por indivíduos individualizados, por sujeitos isolados. Os saberes pedagógicos resultam, em boa parte, da articulação desses processos que possibilitam classificações e hierarquizações de sujeitos e saberes, as quais costumam ser aceitas como algo dado, como "naturais".
Para avançar em nossa discussão é imprescindível apontar a denúncia que Foucault (2001) faz sobre esta época, da emergência de um certo tipo de poder a colonizar tanto o saber médico quanto o poder judiciário. Trata-se do poder da normalização, estabelecido pelo jogo entre diferentes instituições, estendendo sua soberania em nossa sociedade. $\mathrm{O}$ processo de normalização torna-se fruto da ampliação e refinamento dos saberes sobre a diversidade humana. As marcas da anormalidade, ao longo da modernidade, passam a ser buscadas em cada corpo, para que posteriormente lhes seja atribuído um lugar nas grades das classificações dos desvios, das patologias e das deficiências. Mas, conforme afirma o autor, as dificuldades enfrentadas neste campo não devem ser analisadas a partir de uma suposta natureza das coisas - de alguma propriedade transcendental que presidiria o funcionamento do mundo - e sim da forma como um arranjo é inventado para colocar em ação a norma, por meio de um crescente e persistente movimento de, ao separar o normal e o anormal, marcar a distinção entre normalidade e anormalidade. Segundo Foucault (2001, p. 57), "não se trata de expulsar, trata-se ao contrário de estabelecer, de fixar, de atribuir um lugar, de definir presenças, e presenças controladas. Não rejeição, mas inclusão". Essas diferenças sutis entre os indivíduos que estão doentes ou não, são, portanto, individualização e conseqüente divisão e subdivisão do poder que atinge o "grão fino da individualidade".

Trata-se do ponto em que a ciência da infância é capturada pela psiquiatrização para colonizar a existência, não para estender seu domínio, mas porque encontra ali o instrumento de sua universalização possível. Passa a assumir então o comportamento e seus desvios, tomando como referência o desenvolvimento normativo. $\mathrm{O}$ investimento na infância tornou-se o ponto central de partida do qual a generalização pôdese fazer possível.

Vários mecanismos foram colocados em funcionamento na escola moderna, no currículo e na organização didática, com a finalidade de fixar os sentidos sobre quem somos nós - normais - e quem são os outros - os anormais -, a partir da referência a este desenvolvimento normativo.

Segundo a análise de Veiga-Neto (2001), o conceito de nível cognitivo, enquanto operador do movimento que marca a distinção entre normalidade e anormalidade, pode ser compreendido como uma invenção necessária para pôr em prática os saberes disciplinares e a disciplinarização dos sujeitos. Não se trata de um dado natural, mas sim de um arranjo entre saberes e sujeitos que compõe as duas faces do processo disciplinar que atravessa a organização escolar. 
No momento em que avançamos em direção às sociedades pós-disciplinares, esse processo continua vigente através do currículo escolar. $\mathrm{O}$ rompimento da organização por matérias fechadas em direção de unidades temáticas não dissocia o controle dos saberes e dos sujeitos. Os códigos psicopedagógicos reclamam para si o conhecimento da criança, estabelecendo-se, assim, os estágios de desenvolvimento e capacidades cognitivas em função de um pretendido processo de maturação mental, por meio do qual perpetuam uma espécie de normalização dos sujeitos e dos saberes. Os saberes - objeto de transmissão - são sacrificados em favor das destrezas cognitivas.

Silva (1998) analisa, com base em Foucault, as chamadas tecnologias de auto-regulação ou tecnologias de subjetividade autoproclamadamente libertárias a partir do neoliberalismo e do processo de autonomização da sociedade, de auto-regulação, e do deslocamento do foco do Estado para as inúmeras estratégias de controle de conduta espalhadas nos interstícios do social em nome da autonomia e da transferência do controle para o indivíduo. $\mathrm{O}$ autor identifica a teoria construtivista como a orientação central das reformas pedagógicas presentes em todas as partes do mundo, inscrevendo-a entre as pedagogias de inspiração psicológica em um conjunto de pedagogias libertárias, autonomistas e emancipatórias que têm como pressuposto a oposição entre as estruturas de poder e dominação, de um lado, e a ação autônoma do indivíduo ou grupo, de outro. O uso das devidas estratégias é, em si, a fonte de oposição ao poder, e permite ao indivíduo libertar-se dos efeitos das ações das estruturas de poder e opressão. O questionamento central do autor dirige-se ao pressuposto da filosofia da consciência nela contida, ou seja, de uma subjetividade nuclear e original que se opõe às estruturas de poder, o que lhe possibilita ser tratada fora do discurso. Para o autor não há como opor subjetividade e poder, uma vez que ela é artefato das relações de poder, o que explica o termo tecnologia de subjetividade - subjetividade como efeito, não como origem.

Assim, a criança não existe como um fato da natureza, descoberto por um pesquisador, mas como efeito das estratégias discursivas. Tal natureza discursiva não teria importância não fossem seus efeitos de poder, pois a criança produzida pelo construtivismo como um ser raciocinante normal constitui-se em um dispositivo de normalização, o qual efetua processos vitais de inclusão e exclusão.

As reflexões do autor estendem-se a todas as pedagogias, inclusive às críticas, pois mesmo estas opõem subjetividade às estruturas de poder, ou seja, investem em uma subjetividade imanente, cuja constituição é concebida como independente do discurso que a produz, sobremaneira do discurso pedagógico. A consciência, ou o sujeito autocentrado, ocupa um papel central nas mais diversas pedagogias que têm atravessado o pensamento educacional. A oposição binária que contrapõe as pedagogias da repressão às pedagogias libertadoras apenas revela a existência de uma essência a ser reprimida ou libertada. Neste bojo estão as pedagogias críticas, pois a noção de conscientização, cara a algumas de suas importantes correntes, está vinculada à suposição da existência de uma consciência unitária, autocentrada, momentaneamente alienada e mistificada, à espera da desalienação (Silva, 1994, p. 246).

Desse modo, considera-se importante dar visibilidade aos fenômenos psíquicos a partir da história das interações configuradas pelos discursos que permeiam a vida da criança na escola, compreendendo-a em seus modos de produção subjetiva como instituição constitutiva de subjetividades. Como consequiência, faz-se necessária uma discussão que revele outras dimensões para a compreensão/investigação e análise dos problemas que surgem na escola, assim como de suas relações com os processos de inclusão/exclusão escolar autorizados por estes discursos. Os distúrbios, desvios e deficiências surgem como efeitos desses discursos, isto é, das formas como se atribuem sentidos à experiência da criança em face do letramento escolar. Surgem, assim, sob efeitos do poder de nomear, de atribuir identidades normais e anormais ou patológicas.

É nesse cenário que se professa a inclusão escolar, como garantia de avanços em nossa democracia; como forma de assegurar o direito inalienável de uma educação para todos. Requer, contudo, uma análise em profundidade, para que não se restrinja apenas a uma forma de garantir a presença da diferença, construída sobre a idéia de fixação de identidades, e sob o efeito de sedimentação das fronteiras que separam normalidade/anormalidade. Uma inclusão excludente. Esta forma de inclusão/exclusão pode representar o bálsamo tranqüilizante pelo qual a modernidade se confessa de sua brutalidade colonial, redimindo-se de suas práticas de exclusão radical para com seus alunos inventariados como deficientes ou desviantes, todos colocados fora das salas de aula do ensino regular em função de suas diferenças. Esta contradição representa o risco com o qual a escola contemporânea vive seu principal desafio, uma vez que a inclusão pensada em termos de atribuição e fixação de identidades não supera o binômio normalidade-anormalidade, apenas assegura uma forma de se garantir presenças, porém presenças controladas, pois pressupõe o controle da alteridade, e nega a possibilidade de a criança ser considerada sujeito de seu devir. 
Assim, a experiência infantil a ser apreendida na relação constitutiva criança-escola requer, a nosso ver, uma análise que leve em conta os sentidos que as teorias imprimem ao reeditar a ordem natural do desenvolvimento humano, bem como seus efeitos de dominação sobre as práticas pedagógicas e sobre os modos de subjetivação que promovem.

Estas reflexões levam-nos a pensar que a criança, objeto do discurso científico e pedagógico a partir do século XVIII, é produzida por essa ordem do discurso que a gerou. É possível pensar, ainda, que por meio destes discursos e dos fundamentos mais avançados das teorias que os alimentam, a instituição escolar atualiza estratégias de normalização.

Nesse sentido, a psicologia inscreve-se entre as disciplinas que inspiram a criação de pedagogias psicologizantes, como modelo explicativo da infância e da natureza do desenvolvimento da criança, bem como, e simultaneamente, como modelo explicativo de operação dos dispositivos cognitivos. Em suas mais diversas versões, partilham da criação de tecnologias da subjetividade e dos dispositivos de normalização.

Essas considerações permitem-nos afirmar que os sentidos da infância dominantes na escola orientam-se por pressupostos cognitivos e por uma visão de criança hoje chamada de cartesiana, criando uma ilusão de total autonomia em relação a sua constituição, desenvolvimento, linguagem e pensamento. Esses sentidos, fundamentados em uma explicação psicológica e evolutiva da infância, enfatizam ora o amadurecimento da criança - fazer aflorar sua natureza - ora o fazer operar os dispositivos da razão.

\section{CONSIDERAÇÕES FINAIS}

Ao longo de nossas discussões argumentamos que os efeitos da escola na vida da criança são disciplinadores, e que os discursos que lá circulam são constitutivos dos modos de subjetivação infantil. Analisamos o processo de teorização da infância fundamentada na razão iluminista e presente no discurso escolar (pedagógico), que acaba por constituir a trajetória das nossas crianças para a vida adulta. Delineamos, também, as relações que podemos estabelecer entre os desvios, os distúrbios e o discurso escolar, acenando a possibilidade de pensarmos que a teorização da infância em seus modelos mais avançados constitui dispositivos de normalização que fortalecem a barra entre o normal e o patológico, apontando o risco e a contradição em que se desenha a proposta de inclusão escolar.

A criança pensada teleologicamente em termos de previsibilidade e utilidade, enquanto projeto do ser de amanhã, alocada em uma temporalidade linear, e significada dentro do binômio normalidade-anormalidade, foi problematizada em nosso estudo. Com isso podemos afirmar que ela não é a descoberta da ciência, mas efeito de seus discursos, especialmente pelos procedimentos institucionais que atualizam estratégias de normalização, produzindo modos de subjetivação que implicam inclusão/exclusão. As palavras produzem efeitos de sentidos, criam realidades e podem tornar-se potentes mecanismos de subjetivação.

Considera-se necessário, assim, dar visibilidade às estratégias discursivas que produzem binarismos geradores de processos de inclusão/exclusão; que fixam sentidos sobre a experiência cotidiana da criança na escola, colocando suas formas de expressão na mais absoluta previsibilidade, o que é incompatível com a alteridade. Se as teorias que enredam os sentidos da existência da criança na escola colocam-na diante da impossibilidade de ser pensada em sua experiência concreta com a vida, em seu devir, então devemos buscar uma outra possibilidade de pensá-la, e, em última instância, de pensarmos a nós mesmos, nos posicionando em favor do acontecimento da vida.

Para explorar uma outra possibilidade, digamos que mais existencial (sem ser existencialista) e mais estética (sem ser esteticista), seguindo os passos de Jorge Larrosa (2005), podemos pensar a criança e a educação a partir do par "experiência" e "sentido", apostando na necessidade não somente de "raciocinar", "calcular", "argumentar", mas, sobretudo, de pensar no modo como damos sentido ao que somos e ao que nos acontece.

Gagnebin (1994, p. 93) analisa a obra de W. Benjamin, Infância em Berlin por volta de 1900 (1933), levando-nos a pensar a forma com que a experiência da infância guarda o que há de essencial ao homem em relação a seu desajustamento diante do mundo, especificamente no que toca à percepção infantil, o que a torna, aos olhares dos adultos, "ingênua, incompleta e canhestra". Na interpretação da autora a obra propõe muitos exemplos desta "incompetência infantil reveladora de uma verdade que os adultos não podem nem querem ouvir". "Verdade política da presença constante e subterrânea dos vencidos, humilhados." Desta forma, a experiência da infância nos permite refletir, de um outro ângulo de visão, sobre as diferenças na escola, oferecendo-nos uma das chaves para a sua ressignificação.

Tal possibilidade implica o sentido. Mikhail Bakhtin (1992) tem nos apontado o sentido como uma direção para o restabelecimento do laço entre o ser humano e a vida, o qual só se estabelece pela via da 
linguagem; não a linguagem reduzida a um veículo de comunicação, mas por sua dimensão polissêmica, em sua potencialidade constitutiva e instauradora dos múltiplos sentidos que recobrem nossa experiência cotidiana.

No percurso teórico que temos construído buscamos uma compreensão mais globalizante das realidades humanas, abrindo caminhos para pensar a infância a partir de uma complexa reflexão que possa acomodar a heterogeneidade, a plurivocidade, a multivalência, o movimento incessante, a plasticidade, o conflito, o sempre inconcluso.

É a análise do sentido da experiência - matériaprima social-humana - que instaura a relação do homem com a vida; que diferencia o singular do coletivo. Essa dimensão tem por fundamento a intersubjetividade e a relevância da alteridade. Um grande desafio para o novo milênio!

\section{REFERÊNCIAS}

Ariès, P. (1981). História social da criança e da família (2a ed.). Rio de Janeiro: LTC.

Bakhtin, M. (1992). Estética da criação verbal. São Paulo: Martins Fontes.

Castro, L. R. \& Jobim e Souza, S. (1994). Desenvolvimento humano e questões para um final de século: tempo, história e memória. Psicologia Clínica: Pós-graduação e Pesquisa, 6(6), 99-124.

Enguita, M. (1989). A face oculta da escola: Educação e trabalho no capitalismo. Porto Alegre: Artes Médicas.

Foucault, M. (1987). Vigiar e punir (25 ed.). Petrópolis: Vozes.

Foucault, M. (2001). Os anormais: curso no Collège de France (1974-1975). São Paulo: Martins Fontes.

Gagnebin, J. M. (1994). História e narração em Walter Benjamin. São Paulo: Perspectiva, FAPESP; Campinas: Editora da Universidade Estadual de Campinas.
Gagnebin, J. M. (1997). Sete aulas sobre linguagem, memória e história. Rio de Janeiro: Imago.

Horkheimer, M. \& Adorno, T. W. (1985). Dialética do esclarecimento: Fragmentos filosóficos. Rio de Janeiro: Jorge Zahar.

Jobim e Souza, S. (1994). Infância e linguagem: Bakhtin, Vygotsky e Benjamin. Campinas (SP): Papirus.

Jobim e Souza, S. (1996). Re-significando a psicologia do desenvolvimento. Em S. Kramer \& M. I. Leite (Orgs.), Infância: fios e desafios da pesquisa (pp. 39-54). São Paulo: Papirus.

Jobim e Souza, S. (2000). Subjetividade em questão: a infância como crítica da cultura. Rio de Janeiro: 7 Letras.

Larrosa, J. (2004). Notas sobre a experiência e o saber da experiência. Em C. M. G. Geraldi, C. R. Riolfi \& M. F. Garcia (Orgs.), Escola viva: elementos para a construção de uma educação de qualidade (pp. 113-132). Campinas (SP): Mercado das Letras.

Lewontin, R. C., Rose, S. \& Kamin, L. J. (1984). Genética e política. Lisboa: Publicações Europa-América.

Pereira, R. M. R. \& Jobim e Souza, S. (1998). Infância, conhecimento e contemporaneidade. Em S. Kramer \& M. I. Leite (Orgs.), Infância e produção cultural (pp. 25-42). Campinas: Papirus.

Silva, T. T. (Org.) (1994). O sujeito da educação (4 ed.). Petrópolis: Vozes.

Silva, T. T. (Org.) (1998). Liberdades reguladas: a pedagogia construtivista e outras formas de governo do eu. Petrópolis: Vozes.

Varela, J. (1994). O estatuto do saber pedagógico. Em T. T. Silva (Org.), O sujeito da educação (4a ed.) (pp. 87-96). Petrópolis: Vozes.

Veiga-Neto, A. (2001). Incluir para excluir. Em J. Larrosa \& C. Skliar (Orgs.), Habitantes de Babel: políticas e poéticas da diferença (pp. 5-118). Belo Horizonte: Autêntica

Recebido: 30/09/2005 Revisado: 05/11/2005 Aceito: 15/11/2005

\section{Sobre os autores:}

Miriam Aparecida Graciano de Souza Pan: Departamento de Psicologia da Universidade Federal do Paraná. (panpsico@netbank.com.br)

Carlos Alberto Faraco: Programa de Pós-Graduação em Letras da Universidade Federal do Paraná.

(carlosfaraco@netpar.com.br) 